\title{
Prioritization of NFRs using Multi-Criteria Decision Making Methods
}

\author{
Yahiya Gazi \\ M. Tech. Scholar, Department of Computer Science \\ and Engineering, \\ Faculty of Engineering and Technology, \\ Al-Falah University, Dhauj, Faridabad, Haryana, \\ India
}

\author{
Mohd. Sadiq \\ Computer Engineering Section, UPFET, \\ Jamia Millia Islamia (A Central University), New \\ Delhi-110025 \\ India
}

\begin{abstract}
The software engineering is divided into two parts functional requirements (FRs) and non-functional requirements (NFRs) objective of this paper is to classify the Prioritization of Non Functional Requirements (NFRs) by using multi criteria decision making (MCDM) methods. Recently the MCDM are very important for selection of best optimal solution among the different substitutes. Decision making methods (DMM) are selection tools for the managers or decision makers to make future better plans by using qualitative or quantitative data. In this research we take an example of "Institute examination system (IES)" a general idea about DMM and comparison between the two important models, Prioritization of (NFRs) and (MCDM) by using Analytical Hierarchy Process (AHP) method. The research was done by using the information in the literature and expert review. This paper can be used by academics as a foundation for further research and development in the area of decision making models. Decision makers can use this paper for choosing the right DMM in a variety of constraints, such as money and time etc. It can also be used for further development in making standard operational decision making procedures in critical situations.
\end{abstract}

\section{Keywords}

Non-functional Requirements (NFRs), Multi Criteria Decision Making (MCDM), and Analytic Hierarchy Process (AHP).

\section{INTRODUCTION}

Non-functional requirements (NFRs) explain essential constraints upon the development of the proposed system. They identify a wide range of qualities such as security requirements, performance requirements, availability requirements, and adoptability requirements; and these qualities play a key role in driving architectural design [1]. At the time of requirement elicitation, NFR may be

conflicted with each other. For example, accuracy and performance are conflicted NFRs [5].

In literature, we have identified some classification schemes of NFRs [5, 6], for example, ISO/IEC 9126 classified NFRs into four levels, i.e., "quality in use, external quality, internal quality and process quality". Existing classification schemes $[2,3,6]$ do not provide NFRs taxonomy according to the type of system like institute examination system. For example, at the time of requirements elicitation, it is important to know that, how many NFR would be there if we want to develop different types of systems? Therefore, it motivates us to present the classification schemes of NFR for institute examination system development only. This paper is organized as follows: In section II we discuss the literature review of NFRs. Section III presents MCDM. Section IV presents the overview of AHP methods and its techniques. In section $\mathrm{V}$, we explain how the proposed method is important at the time of prioritization of NFR. Case Study is given in section VI. Finally, conclusion and future work are given in section VII.

\section{NON FUNCTIONAL REQUIREMENTS}

This section presents a literature review of NFRs. In literature, we have identified different types of NFRs. For example, the standard ISO/IES 9126 [3] distinguish 4 types of quality levels. Peach et al. [9] provides the following process oriented classification: (i) "The identification of NFR from different viewpoints and different levels of detail", (ii) "The support for uncovering dependencies and conflict between them, and discuss and prioritize them accordingly", (iii) "The documentation of NFR and the evaluation of this documentation", (iv) "The support for identifying means to satisfy the NFR, to evaluate and discuss means, and to make trade -off decision according this includes cost estimation", (v) "The support for change and project management.". In [6] we identify another classification based on the concept of NFR framework [7] proposed by Jureta et al [4] "This scheme was based on "goals and softgoals", driven by the nonbehavioral perspective". This classification includes four categories of goals: functional hardgoals, non-functional hard goals, functional soft goals and nonfunctional soft goals.

\section{MCDM}

The MCDM play a vital role for analyze complex real problems due to their inherent capability to reviewer dissimilar substitutes (selection, approach, plan, situation can also be used synonymously) on a variety of criterion for possible choice of the optimum solution [8]. These Substitutes may be further explored in detail for their final completion. It has become more and more difficult to see the world around us in a uni-dimensional way and to use only a single criterion when judging what we see [10].Many regulatory problems involve multiple objectives and goals. For example: a chemical eradication measure for an exotic invasive species involves concerns such as:

- $\quad$ First Aid

- $\quad$ Illness

- Atmospheric Reaction

- Making cost

There are some types of MCDM methods that can be used to 
make easy individual or group decision-making:

- $\mathrm{AHP}$

- $\quad$ AHP Combined Method

- $\quad$ Fuzzy AHP

- $\quad$ Fuzzy AHP Combined

- $\quad$ Fuzzy AHP Group

We shall focus on the Analytic Hierarchy Process (AHP): AHP was first introduced by Thomas Saaty in 1970s. The approach is to structure a problem as a hierarchy, or a set of integrated levels. Problems are structured in at least three levels: The goal: what will AHP measure, e.g., prioritize organisms for Survey activities. The criteria: elements integral to attaining the goal, e.g., biological effects. The Substitutes : the organisms of concern requires individual or group to provide judgments about relative importance of each criterion; Then specify a preference for each alternative on each criterion.

\section{THE AHP METHOD}

The Analytic Hierarchy Process (AHP) has been developed by T. Saaty (1977) and is one of the best known and most widely used MCA approaches [14]. It allows users to assess the relative weight of multiple criteria or multiple options against given criteria in an intuitive manner. In case quantitative ratings are not available, policy makers or assessors can still recognize whether one criterion is more important than another. Therefore, pair wise comparisons are appealing to users[16]. Saaty established a consistent way of converting such pair wise comparisons ( $\mathrm{X}$ is more important than $\mathrm{Y}$ ) into a set of numbers representing the relative priority of each of the criteria. It is a multi-criteria decision making method for complicated and unstructured problems and also it is an approach that uses a hierarchical model having levels of goal, criteria, possible sub-criteria, and alternatives. The AHP, can be stated, a decision - making and estimation method which gives the percentage distribution of decision points according to factors affecting decision, that is used if there is a defined decision hierarchy.

\subsection{Four Major Steps in Applying the AHP Technique are}

1. Develop a hierarchy of factors impacting the final decision. This is known as the AHP decision model. The last level of the hierarchy is the three candidates as an alternative.

2. Elicit pair wise comparisons between the factors using inputs from users/managers.

3. Evaluate relative importance weights at each level of the hierarchy.

4. Combine relative importance weights to obtain an overall ranking of the three candidates [19].

While comparing two criteria we follow the simple rule as recommended by Saaty (1980). Thus while comparing two attributes $\mathrm{X}$ and $\mathrm{Y}$ we assign the values in the following manner based on the relative preference of the decision maker in this case the HR Managers.
Table 1: Pair wise Comparison

\begin{tabular}{|l|l|}
\hline Intensity of Importance & Definition \\
\hline 1 & Low \\
\hline 2 & Weak \\
\hline 3 & Medium \\
\hline 4 & Strong \\
\hline 5 & Very Strong \\
\hline 6 & Very Highly Strong \\
\hline
\end{tabular}

\section{Advantages of AHP Method}

The advantages of AHP over other multi criteria methods are its flexibility, intuitive appeal to the decision makers and its ability to check inconsistencies [12]. Generally, users find the pair wise comparison form of data input straightforward and convenient.

1. AHP helps to capture both subjective and objective evaluation measures. While providing a useful mechanism for checking the consistency of the evaluation measures and alternatives, AHP reduces bias in decision making.

2. The AHP method supports group decision-making through consensus by calculating the geometric mean of the individual pair wise comparisons [15].

3. AHP is uniquely positioned to help model situations of uncertainty and risk since it is capable of deriving scales.

\section{PROPOSED METHOD}

In this section, we present our prioritization scheme of NFRs. In the proposed classification, we classify the NFRs on the basis of the following criteria, i.e., important NFRs for Institute examination System, Commonly used NFRs similar to some conflicted NFRs. A tree like structure of the proposed classification scheme is given in Fig. 1.

\subsection{Commonly used NFRs}

In literature, we have identified some NFRs that are indispensible for the development of every IS like performance, reliability, usability, security, and maintainability [23].

\subsection{NFRs Definitions and attributes}

In this criterion, we identified those NFRs of IES which are defined with attributes like accessibility, adoptability, availability and efficiency [23].

\subsection{Conflicted NFRs}

In this criterion, we identified those NFRs of IES which is conflicted to the system which is further divide into absolute and relative conflicts like accuracy, reliability and performance [24]. 
Table 2: Evaluation of weights for NFRs by AHP method

\begin{tabular}{cccccc}
\hline NFRs & $\mathrm{DM}_{1}$ & $\mathrm{DM}_{2}$ & $\mathrm{DM}_{3}$ & $\mathrm{DM}_{4}$ & $\mathrm{DM}_{5}$ \\
\hline Accessibility, & $\mathrm{VH}$ & $\mathrm{H}$ & $\mathrm{H}$ & $\mathrm{M}$ & $\mathrm{H}$ \\
Adaptability & $\mathrm{H}$ & $\mathrm{M}$ & $\mathrm{M}$ & $\mathrm{L}$ & $\mathrm{M}$ \\
Availability & $\mathrm{VH}$ & $\mathrm{H}$ & $\mathrm{VH}$ & $\mathrm{VH}$ & $\mathrm{H}$ \\
Effectiveness & $\mathrm{M}$ & $\mathrm{M}$ & $\mathrm{L}$ & $\mathrm{H}$ & $\mathrm{VH}$ \\
Accuracy & $\mathrm{H}$ & $\mathrm{L}$ & $\mathrm{M}$ & $\mathrm{L}$ & $\mathrm{M}$ \\
Efficiency & $\mathrm{M}$ & $\mathrm{H}$ & $\mathrm{VH}$ & $\mathrm{H}$ & $\mathrm{H}$ \\
Reliability & $\mathrm{VH}$ & $\mathrm{H}$ & $\mathrm{VH}$ & $\mathrm{VH}$ & $\mathrm{M}$ \\
\hline
\end{tabular}

In our proposed work, stakeholders that participate in decision making are identified and we call them $\mathrm{DM}_{1}, \mathrm{DM}_{2}, \mathrm{DM}_{3}$, $\mathrm{DM}_{4}$, and $\mathrm{DM}_{5}$. These decision makers assign vague value to the measuring parameters according to the understanding [21]. Weights for each measuring parameter is calculated as listed in table 2 and table 3. From table 3, we identify, after evaluating of weights for NFRs that satisfaction has the highest priority and effectiveness has the lowest priority [22].

Table 3: Evaluation of weights for NFRs by AHP method

\begin{tabular}{ccccccc}
\hline NFSs & $\mathrm{DM}_{1}$ & $\mathrm{DM}_{2}$ & $\mathrm{DM}_{3}$ & $\mathrm{DM}_{4}$ & $\mathrm{DM}_{5}$ & WEIGHTS \\
\hline Accessibility & $\mathrm{VH}$ & $\mathrm{H}$ & $\mathrm{H}$ & $\mathrm{M}$ & $\mathrm{H}$ & 0.741 \\
Adaptability & $\mathrm{H}$ & $\mathrm{M}$ & $\mathrm{M}$ & $\mathrm{L}$ & $\mathrm{M}$ & 0.500 \\
Availability & $\mathrm{VH}$ & $\mathrm{H}$ & $\mathrm{VH}$ & $\mathrm{VH}$ & $\mathrm{H}$ & 0.741 \\
Effectiveness & $\mathrm{M}$ & $\mathrm{M}$ & $\mathrm{L}$ & $\mathrm{H}$ & $\mathrm{VH}$ & 0.416 \\
Accuracy & $\mathrm{H}$ & $\mathrm{L}$ & $\mathrm{M}$ & $\mathrm{L}$ & $\mathrm{M}$ & 0.450 \\
Efficiency & $\mathrm{M}$ & $\mathrm{H}$ & $\mathrm{VH}$ & $\mathrm{H}$ & $\mathrm{H}$ & 0.733 \\
Reliability & $\mathrm{VH}$ & $\mathrm{H}$ & $\mathrm{VH}$ & $\mathrm{VH}$ & $\mathrm{M}$ & 0.825 \\
\hline
\end{tabular}

\section{CASE STUDY}

In this section we present how the proposed classification of NFRs is useful at the time of requirements elicitation $[11,12]$. In our case study, we use an example of Institute Examination System (IES).

In our prioritization of NFRs, Accessibility, Adaptability, Availability, Security, and maintainability are the actual NFRs of IES. Therefore, these NFRs must be present in the software requirements specification document [18].

Reliability and Availability are safety critical and processcontrolled system, respectively, NFRs for Institute examination System. From our prioritization it is clear that effectiveness is highest priority to the others so it is selected. These NFRs must be elicited during early phase of requirements engineering. Reliability and performance are the important NFRs which are similar to conflicted NFR. Performance, Reliability, usability, security and maintainability are the most important NFRs of IES. At the time of decomposing and refining of the conflicted NFR, it can be further decomposed into Absolute and Relative conflict into Reliability, accuracy and Performance.

\section{CONCLUSION AND FUTURE WORK}

In this paper, we have proposed a method based on Non Functional requirements by using multi criteria decision making methods. The proposed method includes the following steps: identify the non-functional requirements, list of NFRs, eliciting of DM's by using multi criteria decision making method for finding the Institute Examination System's requirements and prioritize these requirements according to the decision makers. In our case study, we identify that NFRs has the highest priority and the lowest priority and satisfaction has the highest priority and effectiveness has the lowest priority. Future work includes the following:

1. To apply proposed method in different modules of IES.

2. To present the comparative study between various goals oriented requirements in MCDM.

3. To extend the proposed method by using MultiCriteria Decision Making methods [17] like TOPSIS, AHP etc. 


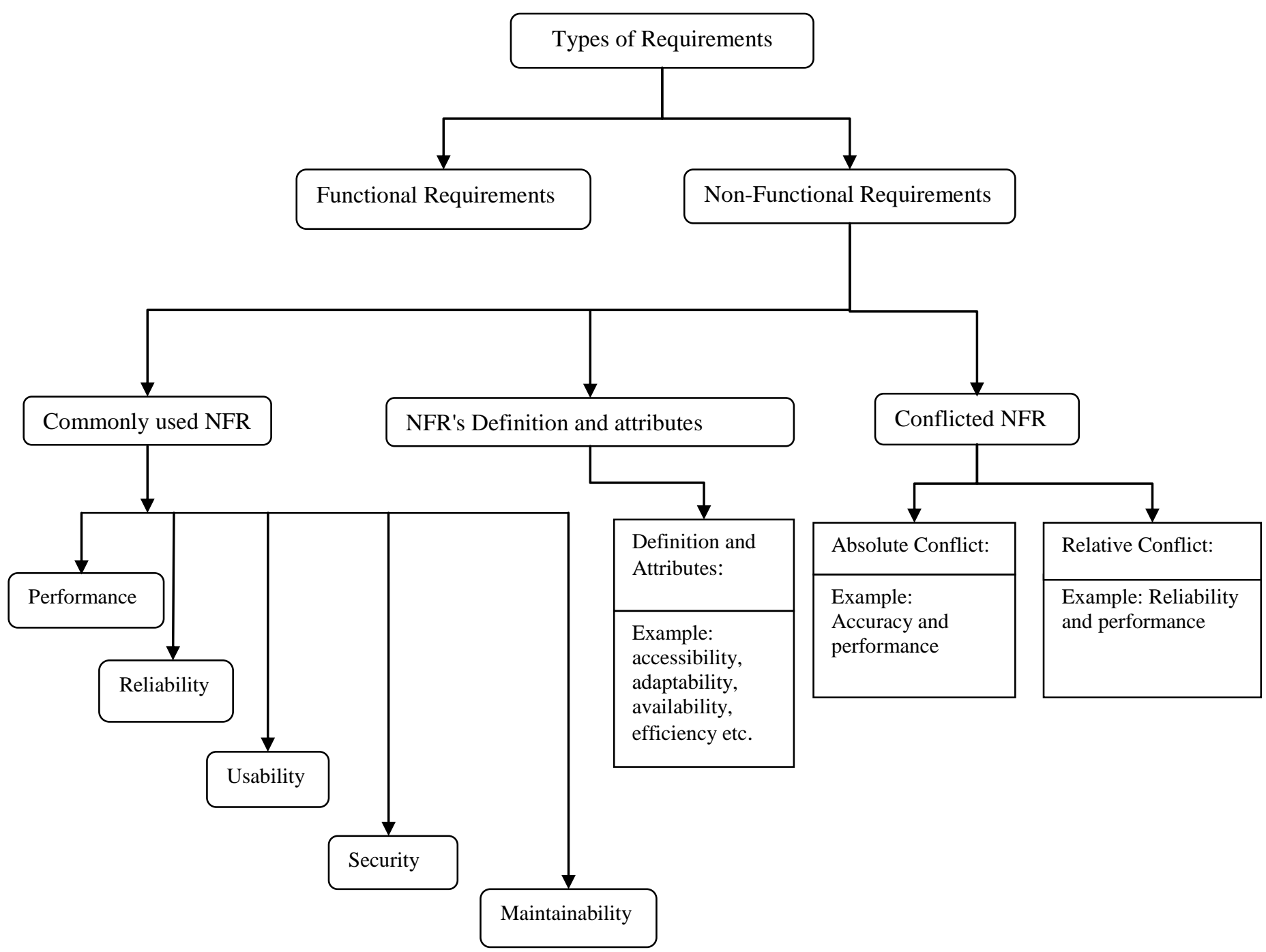

Fig. 1 Prioritization of NFRs

\section{REFERENCES}

[1] Chung L., Leite JCSP "On Non-Functional Requirements in Software Engineering," A.T Borgida et al. (Eds): Mylopoulos Festschrif, LNCS 5600, pp.363-379, SpringerVerlagBerlin Heidelberg 2009.

[2] Grady, R., Caswell, D.: Software Metrics: Establishing a Company-wide Program. Prentice-Hall, Englewood Cliffs 1987.

[3] ISO/IEC 9126-1:2001(E): Software Engineering - Product Quality - Part 1: Quality Model 2001.

[4] Jureta, I.J., Faulkner, S., Schobbens, P.-Y.: A more expressive softgoal conceptualization for quality requirements analysis. In: Embley, D.W., Olivé, A., Ram, S. (eds.) ER, LNCS, Vol. 4215, pp. 281-295. Springer, Heidelberg 2006

[5] Mairiza Dewi and Zowghi Didar, "Constructing a Catalogue of conflicts among Non-functional requirements," L.A Maciaszek and P. Loucopoulos (Eds.):ENASE 2010, CCIS 230,pp.31-44, 2011@Springer-Verlag Berlin Heidelberg 2011.

[6] Mairiza Dewi, Zowghi Didar, Nurmuliani Nurie "An Investigation into the Notion on Non-functional
Requirements," SAC10 pp. 22-26, Sierre Switzerlandm, March 2010.

[7] Mylopoulos, J., Chung, L., Nixon, B.: Representing and Using Nonfunctional Requirements: A Process-Oriented Approach. IEEE Trans. Software Eng. 18(6), pp. 483-497 1992.

[8] Belton, V., Stewart, T.J., 2001: Multiple Criteria Decision Analysis: An Integrated Approach. Kluwer Academic Publishers: Dordrecht.

[9] Paech, B., Kerkow, D.: "Non-Functional Requirements Engineering - Quality is Essential." In: 10th Anniversary International Workshop on Requirements Engineering: Foundationfor Software Quality, REFSQ 2004.

[10] Millet, I., Wedley, W.C., 2002: Modelling Risk and Uncertainty with the Analytic Hierarchy Process. Journal of Multi-Criteria Decision Analysis, 11: 97-107.

[11] Office of the Deputy Prime Minister (ODPM, Government UK, 2004). DTLR multi-criteria analysis manual. Corporate Publication.

internet:http://www.communities.gov.uk/index.asp?id=1142 251

[12] Ramanathan, R., 2001: A note on the use of the analytic 
hierarchy process for environmental impact assessment. Journal of Environmental Management, 63: 27-35.

[13] Rauschmayer, F., 2001: Reflections on Ethics and MCA in Environmental Decisions. Journal of Multi-Criteria Decision Analysis, 10: 65-74.

[14] Saaty, T.L. 1990: How to make a decision: The Analytic Hierarchy Process. European Journal of Operational Research 48: 9-26.

[15] Salminen, P., Hokkanen, J., Lahdelma, R., 1998: Comparing multicriteria methods in the context of environmental problems. European Journal of Operational Research 104: 485-496.

[16] Schmoldt, D., Kangas, J., Mendoza, G.A., Pesonen, M. (eds). 2001.The Analytic Hierarchy Process in Natural Resource and Environmental Decision Making. Kluwer Academic Publishers: Dordrecht.

[17] Vargas, L.G., 1990: An overview of the analytic hierarchy process and its applications. European Journal of Operational Research, 48: pp. 2-8.

[18] Sadiq M. and Jain S.K., "A Fuzzy Based Approach for the Selection in Goal Oriented Requirements Elicitation Process", International Journal of System Assurance Engineering and Management, Springer, 2014.
[19] Sadiq Mohd, Jain S.K, “Applying Fuzzy Preference Relation for Requirements Prioritization in Goal Oriented Requirement".

[20] Sadiq Mohd, "Prediction of Software Project Effort Using Fuzzy Logic", IEEE $3^{\text {rd }}$ International Conference on Electronics, Computer Technology, pp. 353-358, 2014.

[21] Sadiq M and Jain S.K., "A Fuzzy Based Approach for Requirements Prioritization in Goal Oriented Requirements Elicitation Process", International Conference of Software Engineering and Knowledge Engineering (SEKE), pp. 54-58, 2013 USA.

[22] Sadiq M. and Jain S.K., “A Fuzzy Based Approach for the Selection in Goal Oriented Requirements Elicitation Process", International Journal of System Assurance Engineering and Management, Springer, 2014.

[23] Mairiza Dewi and Zowghi Didar, "Constructing a Catalogue of conflicts among Non-functional requirements," L.A Maciaszek and P. Loucopoulos (Eds.):ENASE 2010, CCIS 230, pp.31-44, Springer-Verlag Berlin Heidelberg 2011.

[24] Chung L., "Representing and Using Non-Functional Requirements: A Process Oriented Approach," Ph.D. Thesis, Dept. of Comp. Science. University of Toronto, June 1993. Also tech. Rep. DKBS-TR-91-1. 